Article

\title{
The Development of a Quantitative Precipitation Forecast Correction Technique Based on Machine Learning for Hydrological Applications
}

\author{
Chul-Min Ko ${ }^{1}$, Yeong Yun Jeong ${ }^{1}$, Young-Mi Lee ${ }^{1}$ and Byung-Sik Kim ${ }^{2, *}$ \\ 1 New Business Development Team, ECOBRAIN Co. Ltd., Jeju 63309, Korea; kcm@ecobrain.net (C.-M.K.); \\ jyy@ecobrain.net (Y.Y.J.); leeym@ecobrain.net (Y.-M.L.) \\ 2 Department of Urban \& Environmental Disaster Prevention Engineering, Kangwon National University, \\ Samcheok 25913, Korea \\ * Correspondence: hydrokbs@kangwon.ac.kr; Tel.: +82-033-570-6819
}

Received: 9 December 2019; Accepted: 13 January 2020; Published: 16 January 2020

\begin{abstract}
This study aimed to enhance the accuracy of extreme rainfall forecast, using a machine learning technique for forecasting hydrological impact. In this study, machine learning with XGBoost technique was applied for correcting the quantitative precipitation forecast (QPF) provided by the Korea Meteorological Administration (KMA) to develop a hydrological quantitative precipitation forecast (HQPF) for flood inundation modeling. The performance of machine learning techniques for HQPF production was evaluated with a focus on two cases: one for heavy rainfall events in Seoul and the other for heavy rainfall accompanied by Typhoon Kong-rey (1825). This study calculated the well-known statistical metrics to compare the error derived from QPF-based rainfall and HQPF-based rainfall against the observational data from the four sites. For the heavy rainfall case in Seoul, the mean absolute errors (MAE) of the four sites, i.e., Nowon, Jungnang, Dobong, and Gangnam, were $18.6 \mathrm{~mm} / 3 \mathrm{~h}, 19.4 \mathrm{~mm} / 3 \mathrm{~h}, 48.7 \mathrm{~mm} / 3 \mathrm{~h}$, and $19.1 \mathrm{~mm} / 3 \mathrm{~h}$ for QPF and $13.6 \mathrm{~mm} / 3 \mathrm{~h}, 14.2 \mathrm{~mm} / 3 \mathrm{~h}$, $33.3 \mathrm{~mm} / 3 \mathrm{~h}$, and $12.0 \mathrm{~mm} / 3 \mathrm{~h}$ for HQPF, respectively. These results clearly indicate that the machine learning technique is able to improve the forecasting performance for localized rainfall. In addition, the HQPF-based rainfall shows better performance in capturing the peak rainfall amount and spatial pattern. Therefore, it is considered that the HQPF can be helpful to improve the accuracy of intense rainfall forecast, which is subsequently beneficial for forecasting floods and their hydrological impacts.
\end{abstract}

Keywords: heavy rainfall; machine learning; hydrological application; rainfall correction

\section{Introduction}

As rainfall is a phenomenon with a nonlinear feature, general linear models show a limited accuracy in forecasting it. Unlike conventional statistical techniques, the approach based on machine learning techniques does not require any assumptions. Therefore, machine learning is a very useful technique for analyzing big data and improving the performance of numerical modeling. With the recent availability of greater volumes of climate and meteorological data, various statistical methods based on big data have been developed to reproduce such data into forecasting information, with higher accuracy [1-3]. In addition, a wide range of studies has been conducted using the artificial neural network to improve the quantitative estimation of rainfall with numerical forecasting data. Machine learning is commonly used as a technique for the trial to overcome the limitations in forecasting phenomena, such as localized heavy rains that are required to be accurately predicted in a short period, despite significant forecasting errors [4-7].

Utilizing the Dong-Nae Forecast, which is the meteorological quantitative precipitation forecast (QPF) produced by the Korea Meteorological Administration (KMA), leads to difficulties in analyzing 
the hydrological impact of localized heavy rainfall. Although there are significant local variations occurring in a short period for most of heavy rainfall cases, the QPF shows a limited ability, in terms of its spatial and temporal resolutions. Therefore, a rainfall forecast for hydrological use requires the correction of the systematic bias of rainfall with machine learning, in parallel with efforts made to increase the accuracy of numerical models. The rainfall forecast promptly provided by machine learning will greatly support the emergency management for cities and communities that are vulnerable to disasters during a localized heavy rainfall period.

This study aims to improve the accuracy of rainfall for hydrological purposes (e.g., flood and inundation). For this, the hydrological quantitative precipitation forecast (HQPF) is developed by applying the machine learning algorithm, which is fed with rainfall data provided by the KMA. The main contribution of this study is to provide the potential of the machine learning algorithm as a tool for practical application to improve the performance in forecasting intense and localized rainfall, which suffers from a limited accuracy. Through the verification of two case studies (heavy rainfall in Seoul and heavy rainfall accompanied by Typhoon Kong-rey), our results demonstrate qualitative and quantitative evidence to support the effectiveness of HQPF based on machine learning. Section 2 discusses the data and methodologies, and Section 3 explains the spatial field and time-series analyses and statistical verification for the rainfall forecast results. Sections 4 and 5 provide the discussion and conclusion, respectively.

\section{Materials and Methods}

\subsection{Data Sources}

\subsubsection{Rainfall Observation Data}

This study used the observational data from the Automated Surface Observing System (ASOS) and Automatic Weather Station (AWS). The KMA operates the ASOS of 96 stations and the AWS of 494 sites for the observation of precipitation, temperature, and so on for the Korean peninsula. The data are efficiently used for the quantitative analysis of rainfall characteristics in the country as a whole. This study utilized observation data from three AWS sites to verify the predicted HQPF (details of the sites are shown in Table 1 and Figure 1).

Table 1. Location information of observational sites used for the verification of HQPF.

\begin{tabular}{cccc}
\hline Case Name & Site & Longtitude $\left({ }^{\circ} \mathbf{E}\right)$ & Latitude $\left({ }^{\circ} \mathbf{N}\right)$ \\
\hline \multirow{3}{*}{ Case 1 (Heavy rainfall in } & Nowon & 127.0919 & 37.6219 \\
Seoul) & Jungnang & 127.0868 & 37.5855 \\
& Dobong & 127.0295 & 37.5995 \\
& Gangnam & 127.0467 & 37.5134 \\
\hline \multirow{2}{*}{ Case 2 (Heavy rainfall } & Dangjin & 126.6174 & 36.8894 \\
during Typhoon & Bamsagol & 127.5783 & 35.3716 \\
Kong-rey) & Seosan & 126.2964 & 36.7585 \\
& Taean & 126.4939 & 35.7766 \\
\hline
\end{tabular}

RAR (Radar-AWS Rainrate) is a system that estimates rainfall intensities on a real-time basis using the data from radar and AWS. The system produces quantitative rainfall data with a high resolution for the Korean peninsula. The provided resolutions are the spatial resolution of $1 \mathrm{~km}$ and temporal resolution of $10 \mathrm{~min}$ intervals. 

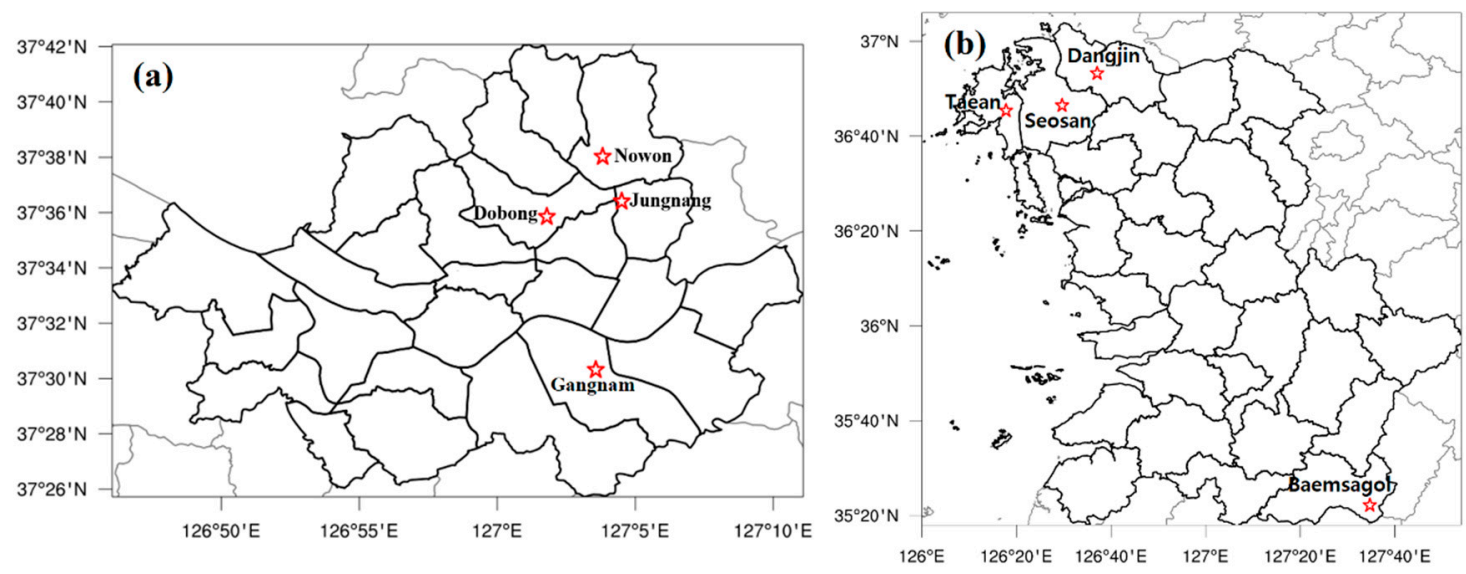

Figure 1. Study areas. The black line on the map denotes the administrative division of city and county unit at (a) Seoul and (b) Chungcheongnam-do and Jeollabuk-do. Red stars indicate the observational sites used for the verification of hydrological quantitative precipitation forecast (HQPF).

\subsubsection{Meteorological Forecasting Data}

In this study, data from the Local Ensemble Prediction System (LENS) and Dong-Nae Forecast were used in developing the algorithm for rainfall correction. The LENS is a local ensemble forecast system based on the unified model (UM), which consists of 13 ensemble members perturbed with different initial conditions and produces forecast information for up to $72 \mathrm{~h}$, predicting probabilities of severe weather in the Korean peninsula. It provides the data with $3 \mathrm{~km}$ of spatial resolution and $1 \mathrm{~h}$ of temporal resolution. LENS is updated every $12 \mathrm{~h}$.

Since 2008, the KMA has provided Dong-Nae Forecast data in detail for each administrative division in South Korea (eup, myeon, and dong). It provides quantitative forecast data, including the temperature, wind speed, rainfall probability, and rainfall types in a $5 \mathrm{~km}$ grid size across the Korean peninsula. This study extracted $6 \mathrm{~h}$ of accumulated rainfall data from the Dong-Nae Forecast which were used as input data for machine learning. These input data were also used for the reference to demonstrate how effectively HQPF can improve the performance.

\subsection{Machine Learning}

\subsubsection{Meteorological Predictors}

The meteorological predictors related to localized heavy rainfall were identified through a literature review. Those predictors suggested by Kang et al. [5] and other additional ones are summarized in Table 2. From the LENS data, the study used three-dimensional spatial data to extract the thickness, upper-level jet, lower-level jet, vertical wind shear, dew point deficit, precipitable water, instability index, vertical velocity, surface temperature, surface wind speed, sea-level pressure, and precipitation. Furthermore, this study used multiple precipitation data from the ASOS, AWS, RAR, and Dong-Nae Forecast data to enhance the quality of input data.

This study converted the spatial resolution of the collected data into $1 \mathrm{~km}$ to use them as input data for machine learning. As the ASOS and AWS are point data, this study used only the data from the model grids with $1 \mathrm{~km}$ or less and interpolated the others into the RAR data. For the Dong-Nae Forecast data, the kriging method was used to convert the spatial resolutions from $5 \mathrm{~km}$ to $1 \mathrm{~km}$. The ensemble mean of the LENS model was used to disaggregate $6 \mathrm{~h}$ accumulated data into $1 \mathrm{~h}$ data. For the LENS data, an accumulation of $6 \mathrm{~h}$, which is the same time as the Dong-Nae Forecast data, was obtained, and then the ratio to the Dong-Nae Forecast was calculated to multiply it with the LENS rainfall data with $1 \mathrm{~h}$ of temporal resolution. 
Table 2. Predictor variables used machine learning.

\begin{tabular}{lc}
\hline \multicolumn{1}{c}{ Input Variables } & Source \\
\hline Atmospheric thickness from $500-1000 \mathrm{hPa}(\mathrm{m})$ & LENS $^{1}$ \\
Wind speed at $200 / 500 / 850 \mathrm{hPa}(\mathrm{m} / \mathrm{s})$ & LENS \\
Vertical wind shear from $200-850 \mathrm{hPa}(\mathrm{m} / \mathrm{s})$ & LENS \\
Dew point temperature at $700 \mathrm{hPa}\left({ }^{\circ} \mathrm{C}\right)$ & LENS \\
K-Index $($ Instability Index) & LENS \\
Precipitable water $(\mathrm{mm})$ & LENS \\
Relative humidity at $850 \mathrm{hPa}(\%)$ & LENS \\
Wind speed at surface $(\mathrm{m} / \mathrm{s})$ & LENS \\
Temperature at surface $\left({ }^{\circ} \mathrm{C}\right)$ & LENS \\
Sea level pressure $(\mathrm{hPa})$ & LENS \\
Vertical velocity at $700 \mathrm{hPa}(\mathrm{hPa} / \mathrm{h})$ & LENS \\
Precipitation $(\mathrm{mm} / \mathrm{h})$ & LENS \\
Precipitation $(\mathrm{mm} / \mathrm{h})$ & ASOS ${ }^{2}$, AWS ${ }^{3}$ \\
Precipitation $(\mathrm{mm} / \mathrm{h})$ & RAR ${ }^{4}$ \\
Precipitation $(\mathrm{mm} / \mathrm{h})$ & Dong-Nae (Digital) Forecast \\
\hline${ }^{1}$ Local ENsemble prediction System. ${ }^{2}$ ASOS: Automated Surface Observing System. 3 AWS: Automatic Weather \\
Station. 4 RAR: Radar-AWS Rainrate.
\end{tabular}

\subsubsection{Extreme Gradient Boosting}

Machine learning was used to identify the nonlinear relationships between the meteorological predictors and calculate the weights. There are two ensemble learning modes of machine learning, bagging and boosting. In the bagging mode, learning data are subject to random sampling for the partitioning, and the final outcome is produced after the weak forecast models are combined. On the other hand, the boosting mode is the algorithm that builds a robust forecast model by weighting error data that could not be predicted with past models. This model differs from the bagging mode by considering the errors of past models. Random forest is the bagging mode, while AdaBoost (Adaptive Boosting), GBM (gradient boosting machine), and XGBoost (eXtreme Gradient Boosting) are examples of the boosting mode. Adaboost is a forecast model that considers weight with the cost function for each of the models. The GBM is conceptually the same as Adaboost, but it applies the gradient descent when calculating weights. XGBoost is superior to the GBM in that its performance is improved with distributed and parallel processing. In general, the speed of XGBoost is 10 times higher than that of the GBM. In addition, this technique provides a realization with expandability in an effective way, so it was often used by preceding studies [8-10]. XGBoost is a boosting technique to decrease error values by combining the classification and regression tree. It is composed as follows:

$$
\hat{y}_{i}=\varnothing\left(x_{i}\right)=\sum_{k=1}^{K} f_{k}\left(x_{i}\right), f_{k} \in F .
$$

Equation (1) represents the forecast model. $K$ is for the number of trees, $F$ for all the regression tree sets of CART (Classification And Regression Trees), and $f$ for the function of the space $F$.

$$
\mathcal{L}(\varnothing)=\sum_{i}\left(\hat{y}_{i}, y_{i}\right)+\sum_{k} \Omega\left(f_{x}\right)
$$

where $\Omega(f)=\gamma T+\frac{1}{2} \lambda\|\omega\|^{2}$.

In Equation (2), the first term of the right side is to measure if the learning data fit well with the model for the forecast model optimization, while the second term is to measure if the model complexities are simplified through the normalization. 


$$
\mathcal{L}^{(t)}=\sum_{i=1}^{n} l\left(y_{i}, \hat{y}_{i}{ }^{(t-1)}+f_{t}\left(x_{i}\right)\right)+\Omega\left(f_{t}\right)
$$

Equation (3) reflects a number of tree results to calculate the loss of the trees for each step.

$$
\mathcal{L}^{(t)} \simeq \sum_{i=1}^{n}\left[l\left(y_{i}, \hat{y}^{(t-1)}\right)+g_{i} f_{i}\left(x_{i}\right)+\frac{1}{2} h_{i} f_{t}^{2}\left(x_{i}\right)\right]+\Omega\left(f_{t}\right) .
$$

Equation (4) shows how the Tayler expansion is used to simplify into the second-order polynomial function, and then the diverse loss functions are put into it to obtain an equation for the step and optimize the learning for the new tree.

$$
\overline{\mathcal{L}}^{(t)}=\sum_{i=1}^{n}\left[g_{i} f_{t}\left(x_{i}\right)+\frac{1}{2} h_{i} f_{t}^{2}\left(x_{i}\right)\right]+\gamma T+\frac{1}{2} \lambda \sum_{j=1}^{\mathrm{T}} w_{j}{ }^{2}=\sum_{j=1}^{T}\left[\left(\sum_{i \in I_{j}} g_{i}\right) w_{i}+\frac{1}{2}\left(\sum_{i \in I_{j}} h_{i}+\lambda\right) w_{j}{ }^{2}\right]+\gamma T .
$$

Equation (5) adjusts the complexity of the model through normalization. All the data that belong to the same leaf have the same score, thus changing an equation to calculate the sum.

$$
\overline{\mathcal{L}}^{(t)}(q)=-\frac{1}{2} \sum_{j=1}^{T} \frac{\left(\sum_{i \in I_{j}} g_{i}\right)^{2}}{\sum_{i \in I_{j}} h_{i}+\lambda}+\gamma T \text {. }
$$

Equation (6) is the minimum objective value (score) for the leaf of the tree. The score makes it possible to evaluate the model (tree structure) with a lower score indicating a better tree structure.

\subsubsection{Parameters and Tool}

To conduct the XGBoost analysis, the model hyperparameters should be adjusted. The range of the hyperparameters extracted by the grid search is shown in Table 3. This study used machine learning to go through different steps, including data preprocessing, calculation, and training. This process was encoded using the $\mathrm{R}$ language package. The purpose of parameter tuning in machine learning is to find the optimal parameters of a model, which can depend on scenarios. From the perspective of bias variance tradeoff, as the model gets more complicated (e.g., more layers), the model shows a better ability to fit into the training data, resulting in a less biased model. However, to avoid the overfitting problem arising from too much training data, we controlled model complexity through the "max_depth" parameter and added randomness to make training robust to noise through the stepsize parameter, "eta", and "nrounds" parameter.

Table 3. Extreme Gradient Boosting regression, which modeled hyperparameters from the grid search.

\begin{tabular}{ccc}
\hline Parameter & Range & Optimum Value \\
\hline max_depth & $2-10$ & 5 \\
eta & $0.1-1$ & 0.5 \\
nrounds & $10-100$ & 50 \\
\hline
\end{tabular}

\subsubsection{Training}

The training for machine learning was conducted using meteorological predictors that had been collected from July to October for the years 2016 and 2017. For the predictors, weights were calculated for rainfall using the XGBoost technique and HQPF was produced by obtaining the average of the ensemble results (Figure 2). 


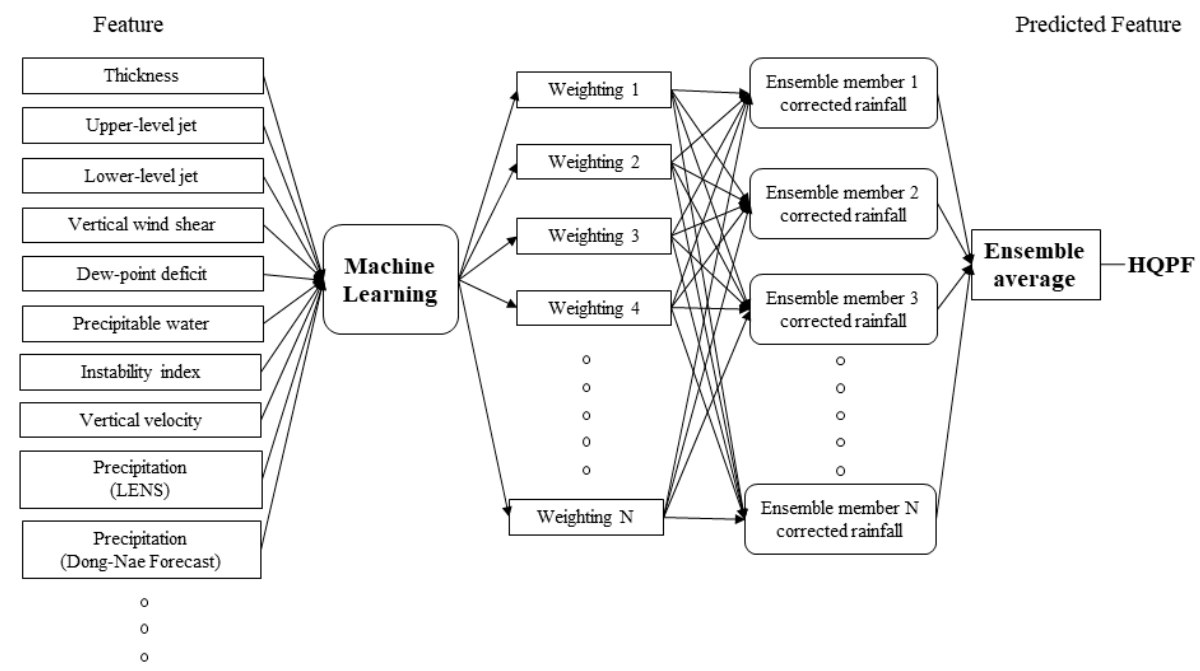

Figure 2. Mimetic diagram for machine learning training.

\subsubsection{Design of HQPF Algorithm}

The HQPF algorithm with rainfall correction was developed through a series of processes, including preprocessing, machine learning, and post-processing, using observation data and numerical forecast data (Figure 3). The design process was as follows. Preprocessing was the first step to extract meteorological predictors from numerical forecast data that would be used as input data for machine learning. In this step, the meteorological predictors mentioned in Sections 2.1.1 and 2.2.2 were extracted from the weather observation data and forecast data. This step also covered the conversion process of spatial and temporal resolution. The second step, machine learning, was to conduct its training by using the meteorological predictors that had been collected from July to October for the years 2016 and 2017. For the meteorological predictors, the XGBoost of the machine learning technique was applied to produce a $1 \mathrm{~h}$ interval of rainfall corrected for each of the ensemble members by inputting the LENS forecast data and Dong-Nae Forecast data. However, the main purpose of HQPF is to provide an improved input for the criteria of precipitation special weather report and heavy rainfall impact model for KMA, which are operated with $3 \mathrm{~h}$ interval accumulated rainfall. In this regard, this study focused on the $3 \mathrm{~h}$ accumulated rainfall. Lastly, during the post-processing, the corrected rainfall values of the ensemble members were averaged and finally HQPF was calculated.

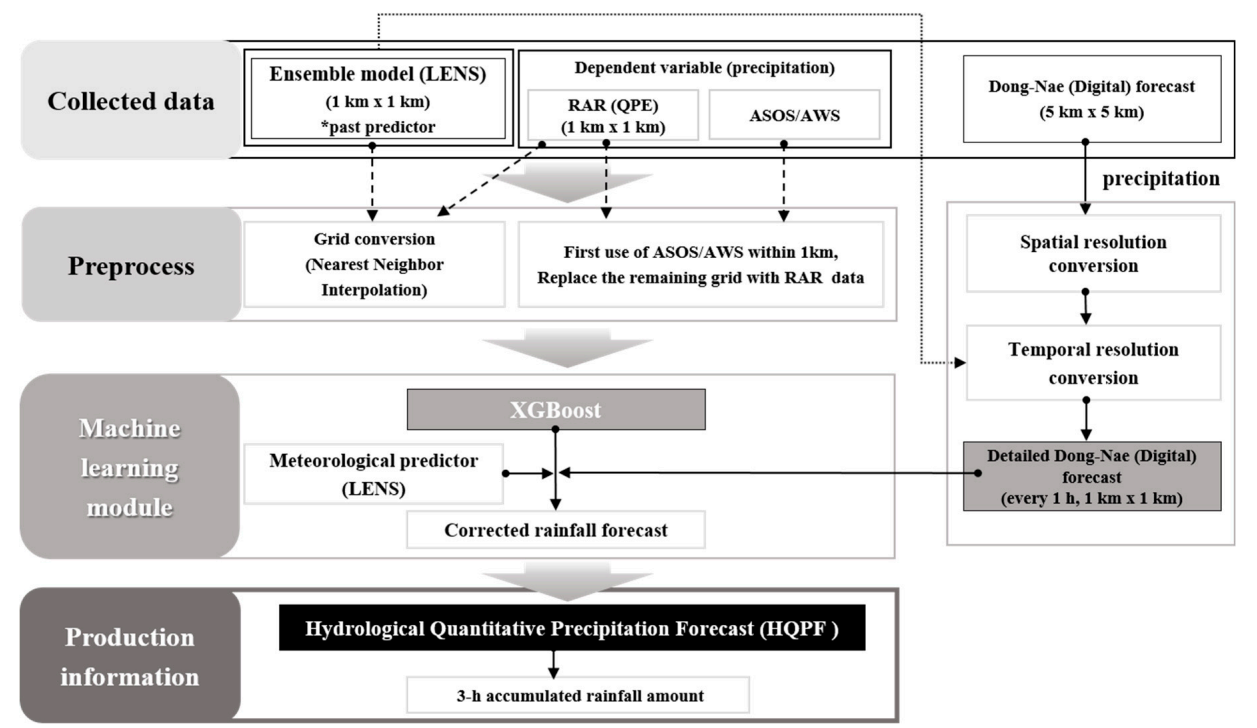

Figure 3. HQPF calculation process. 


\subsection{Selection of Heavy Rainfall Cases}

\subsubsection{Case 1: Heavy Rainfall in Seoul}

This study used the case of localized heavy rainfall at 13:00 on 28-31 August 2018, in Seoul (Figure 4). During the period, a special warning for a heat wave was issued over the southern region. Furthermore, the central region, including Seoul, experienced heavy rain, with over $30 \mathrm{~mm}$ of rainfall per hour, because it is located between the high- and low-pressure system in the atmosphere. The cold air coming from the north and the North Pacific, which is over the southern part of Japan, collided and, at the same time, the tropical cyclone, which included a large amount of water vapor, was moving into the central region of the Korean peninsula from Taiwan by riding the lower jet stream to form the rain belt stretching from the east to the west over the region (Figure 4). The radar images of the KMA show there was the rain belt, which stretched from the east to the west with $20 \mathrm{~mm}$ or more of rainfall. During that period, there was heavy rainfall, with $60 \mathrm{~mm}$ or more per hour in some areas. As shown in Figure 4 (right), the southern part of Seoul, mostly the Hangang river area, experienced rainfall with $5 \mathrm{~mm}$ or less per hour, while in the northern area, heavy rain of $50 \mathrm{~mm}$ or more per hour occurred at the same time period. This heavy rain case was characterized by the high deviation across the region and heavy rain in the area north of the Hangang River, Seoul.
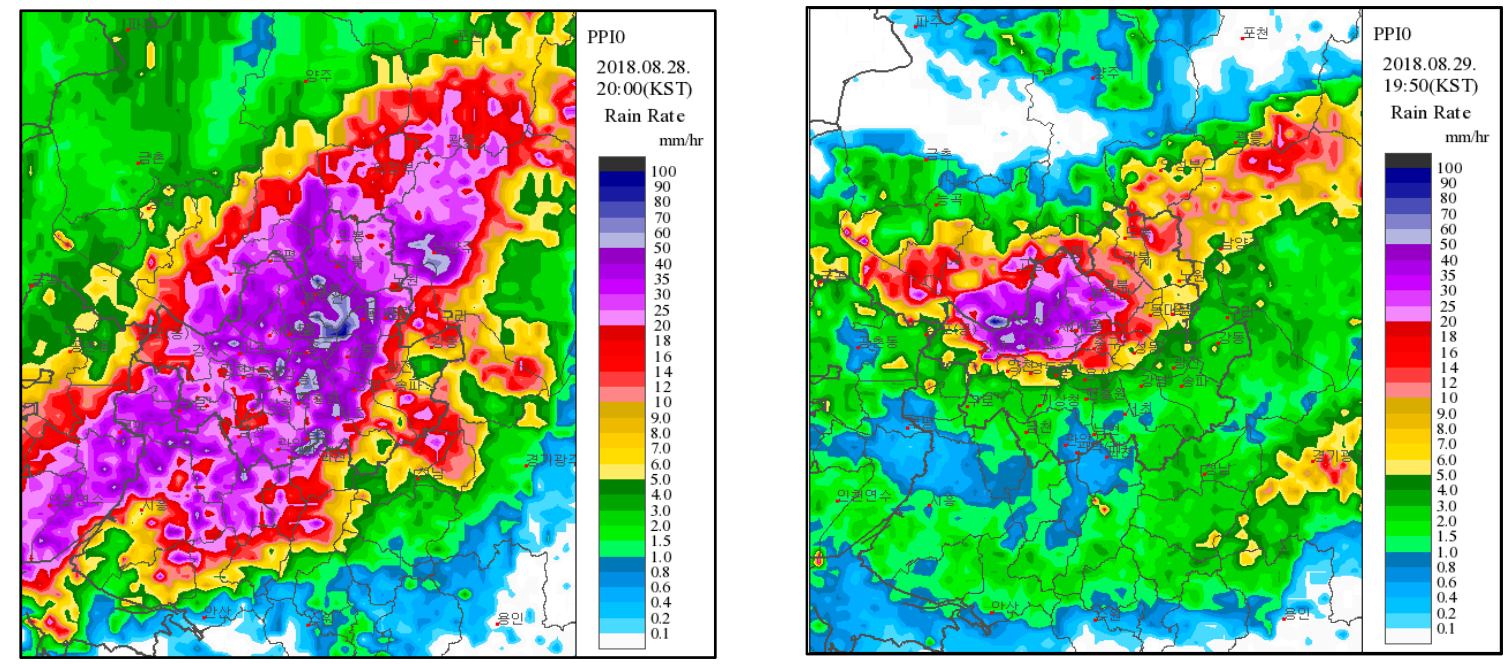

Figure 4. Radar image of the Korea Meteorological Administration (KMA) (left) at 20:00 on 28 August 2018 (KST), (right) at 19:50 on 29 August, 2018 (KST).

In the above radar images, it is shown that localized heavy rain occurred mostly in the area north of the Hangang River, Seoul. Therefore, in this study, four sites of the areas were selected to see the time series for the $1 \mathrm{~h}$ accumulated precipitation (Figure 5). The rainfall information of the four sites, Nowon, Jungnang, Dobong, and Gangnam, is shown in Table 4. The peak rainfall for Nowon and Jungnang occurred at 18:00 and 19:00 on 28 August with $20.4 \mathrm{~mm} / \mathrm{h}$ and $31.1 \mathrm{~mm} / \mathrm{h}$, respectively. For Dobong, the peak precipitation occurred at 00:00 on 30 August with $76.0 \mathrm{~mm} / \mathrm{h}$. The peak precipitation for Gangnam occurred at 21:00 on 28 August with $29.5 \mathrm{~mm} / \mathrm{h}$.

The time series characteristics of observed rainfall for Nowon, Jungnang, and Gangnam included heavy rainfall (I), which was followed by the state of weak rainfall (II). For Dobong, after a few hours of heavy rainfall, weak rainfall did not follow. The accumulated rainfall and intensity are shown in Table 4, with classification for heavy rainfall and, afterward, weak rainfall. In the heavy rainfall sections for Nowon, Jungnang, Dobong, and Gangnam, the accumulated precipitation was $76.0 \mathrm{~mm}$, $74.6 \mathrm{~mm}$, and $309 \mathrm{~mm}, 57.5 \mathrm{~mm}$, respectively. 

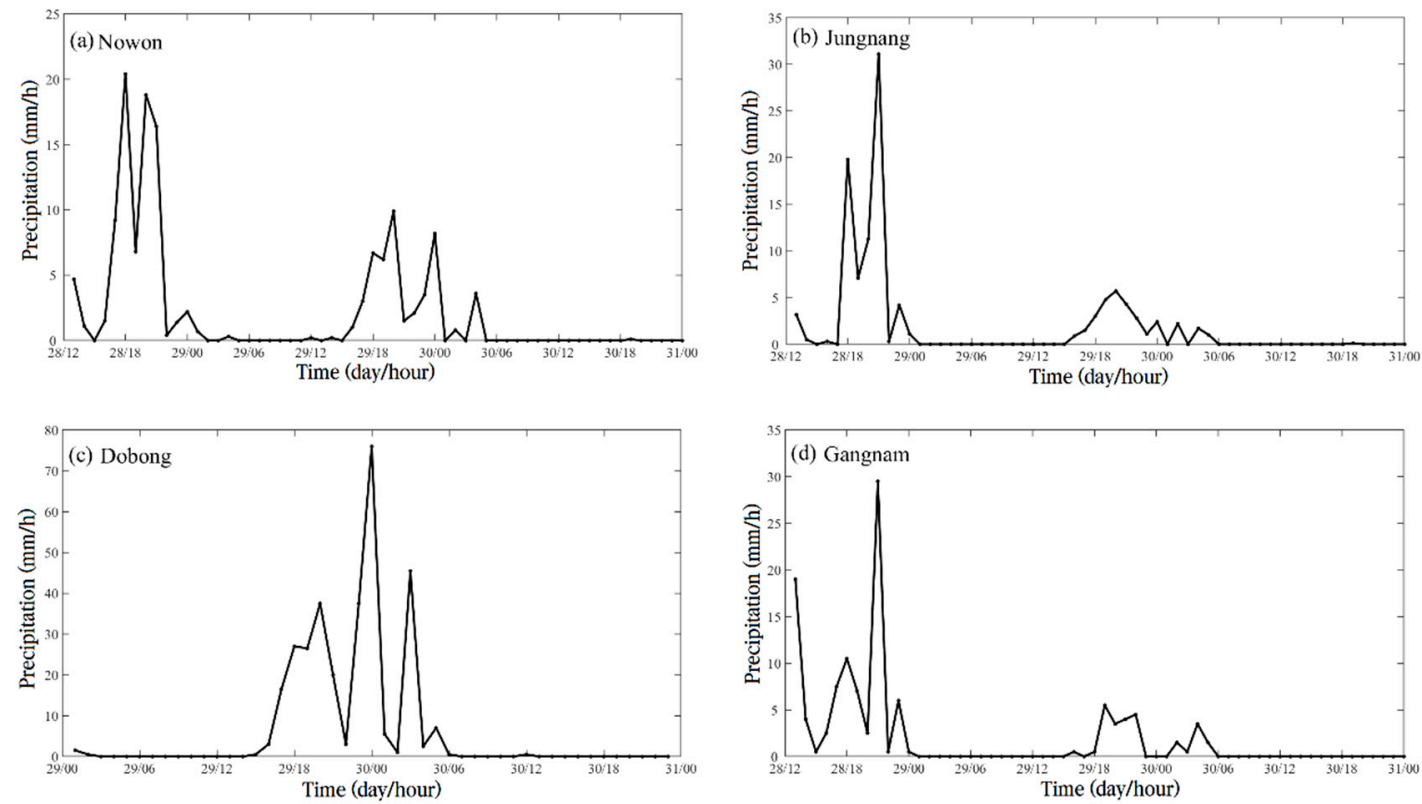

Figure 5. Time series of 1 hour of observed accumulated rainfall at (a) Nowon, (b) Jungnang, (c) Dobong, and (d) Gangnam observational sites.

Table 4. Rainfall information of four sites used for the validation of Case 1.

\begin{tabular}{|c|c|c|c|c|}
\hline Information & Nowon & Jungnang & Dobong & Gangnam \\
\hline Maximum precipitation time (KST) & $18: 00,28$ th & 19:00, 28th & 00:00, 30th & $21: 00,28$ th \\
\hline Peak precipitation $(\mathrm{mm} / \mathrm{h})$ & 20.4 & 31.1 & 76.0 & 29.5 \\
\hline section I (KST) & $14: 00-23: 00,28$ th & $14: 00-23: 00,28$ th & $16: 00-06: 00,29$ th & $17: 00-22: 00,28$ th \\
\hline Accumulated precipitation of section $\mathrm{I}(\mathrm{mm} / \mathrm{h})$ & 76 & 74.6 & 309 & 57.5 \\
\hline Precipitation intensity of section I (mm/h) & 8.44 & 8.29 & 22.07 & 11.5 \\
\hline Rainfall section II (KST) & $15: 00-22: 00,29$ th & $15: 00-22: 00,29$ th & - & $16: 00-23: 00,29$ th \\
\hline Accumulated precipitation of section II $(\mathrm{mm} / \mathrm{h})$ & 30.4 & 23 & - & 18.5 \\
\hline Precipitation intensity of section II $(\mathrm{mm} / \mathrm{h})$ & 4.34 & 3.29 & - & 2.64 \\
\hline Time to start rainfall & $\begin{array}{c}12: 00,28 \text { August } \\
2018\end{array}$ & $\begin{array}{c}12: 00,28 \text { August } \\
2018\end{array}$ & $\begin{array}{c}\text { 00:00, } 29 \text { August } \\
2018\end{array}$ & $\begin{array}{c}\text { 12:00, } 28 \text { August } \\
2018\end{array}$ \\
\hline
\end{tabular}

\subsubsection{Case 2: Typhoon Kong-Rey}

The second case study was about the 25th typhoon, Kong-rey, which occurred on 28 September 2018. When the typhoon approached Jeju island on 6 October, its category was medium-scale typhoon (KMA criteria) with $975 \mathrm{hPa}$ central pressure, $32 \mathrm{~m} / \mathrm{s}$ maximum wind speed, and $350 \mathrm{~km}$ strong wind radius. After that, the typhoon headed north and north-east, it landed with $975 \mathrm{hPa}$ central pressure on the Korean peninsula. As shown in Figure 6, the typhoon brought an intense and narrow rain band with a more than $10 \mathrm{~mm}$ per hour rainfall rate due to the influence of the front of the typhoon before landing on the Korean peninsula. Precipitation was particularly concentrated in the northwestern (about $36-37^{\circ} \mathrm{N}, 127^{\circ} \mathrm{E}$ ) and southeastern (about $35^{\circ} \mathrm{N}, 128-130^{\circ} \mathrm{E}$ ) parts of Korea.

\subsection{Verification Indicators and Methodologies}

This study used three indicators to evaluate the accuracy of the predicted HQPF. The verification indicators included percentage error, mean absolute error (MAE), which indicates the mean error of corrected precipitation, and normalized peak error (NPE), which indicates the maximum error of the predicted HQPF:

$$
\text { Percentage error }=\frac{1}{n} \sum_{i=1}^{n}\left(\frac{\left|O_{i}-E_{i}\right|}{O_{i}}\right) \times 100 ;
$$




$$
\begin{gathered}
\mathrm{MAE}=\frac{1}{n} \sum_{i=1}^{n}\left|O_{i}-E_{i}\right| ; \\
\mathrm{NPE}=\frac{P_{e}-P_{o}}{P_{o}} .
\end{gathered}
$$

In the equation above, $O_{i}$ is for the observed data, $E_{i}$ for the corrected precipitation (HQPF), and $n$ for the number of data. $P_{e}$ and $P_{o}$ indicate the maximum value of the predicted precipitation and the observed, respectively. Equations (7) and (8) are the percentage error value and MAE, respectively, with a lower value indicating a lower deviation between the prediction and the actual value. Equation (9) is an indicator that shows the error for the maximum precipitation value and is best suited to the study's purpose in error analysis.
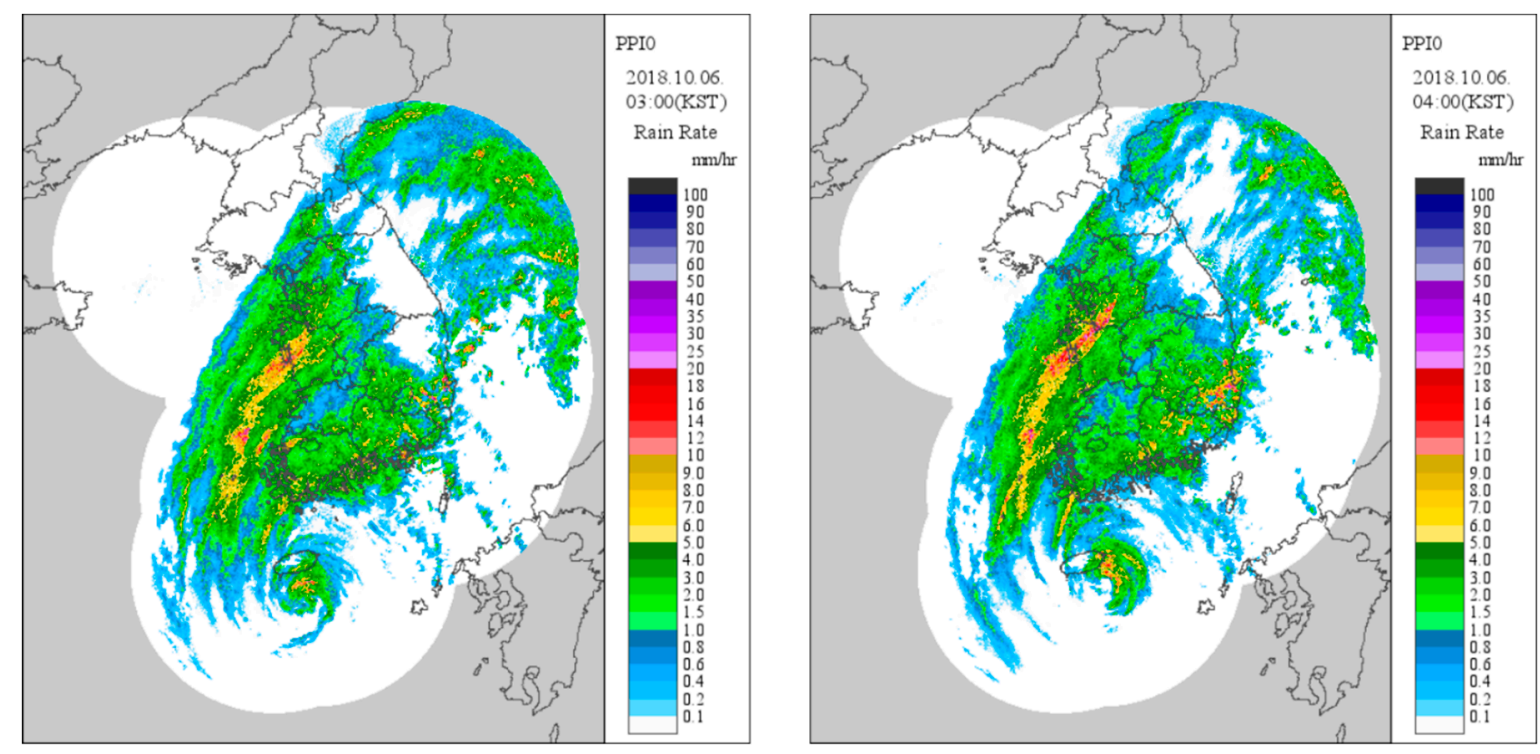

Figure 6. Radar image of KMA (left) at 03:00, and (right) at 04:00 on 6 October 2018 (KST).

\section{Results}

\subsection{Case 1: Rainfall in Seoul}

\subsubsection{Spatial Distribution}

The KMA defines heavy rainfall as precipitation with $60 \mathrm{~mm}$ or more of $3 \mathrm{~h}$ accumulated precipitation. As shown in Figure $7 \mathrm{a}-\mathrm{c}$, about the spatial distribution of $3 \mathrm{~h}$ accumulated precipitation, the heavy rain occurred mainly over the northern part of Seoul. As explained in Section 2.3, during that period, the heavy rain area covered the Nowon, Jungnang, Dobong, and Gangnam sites (marked with a star in Figure 7a-c). As shown in Figure 7d-f, the QPF was not able to forecast heavy rainfall of $10 \mathrm{~mm}$ or more per hour. Although, in Figure 7e,f, the rain rate around $15 \mathrm{~mm}$ per hour was predicted for the northern part, but it still had the limitation of forecasting heavy rain. The HQPF forecasting result of Figure $7 \mathrm{~g}-\mathrm{i}$ shows the heavy rainfall over north Seoul. It simulated the localized heavy rainfall area, which was not the case for the QPF, which suggests that the machine learning enhanced the forecasting performance for localized heavy rainfall.

For the quantitative measure of rainfall accuracy, the percentage error with respect to individual grid points was calculated. Figure 8 presents the spatial distribution of percentage error derived from QPF-based rainfall and HQPF-based rainfall. Consistent with the comparison of spatial distribution of $3 \mathrm{~h}$ accumulated rainfall amount (Figure 7), the percentage error from HQPF-based rainfall was significantly reduced compared to that from QPF-based rainfall. Regardless of selected timing, errors of more than $80 \%$ were predominant in the QPF-based rainfall. In particular, the northern part of 
Seoul maintained a consistently significant error. On the other hand, HQPF-based rainfall remarkably reduced the amount of error. Although some regions still suffered from large error, the majority of the regions clearly revealed the reduction in error. One notable deficiency was seen in the southern part of Seoul on 29 August. This was because the HQPF tends to overestimate weak precipitation compared to what is observed, which will be further improved by our future study.
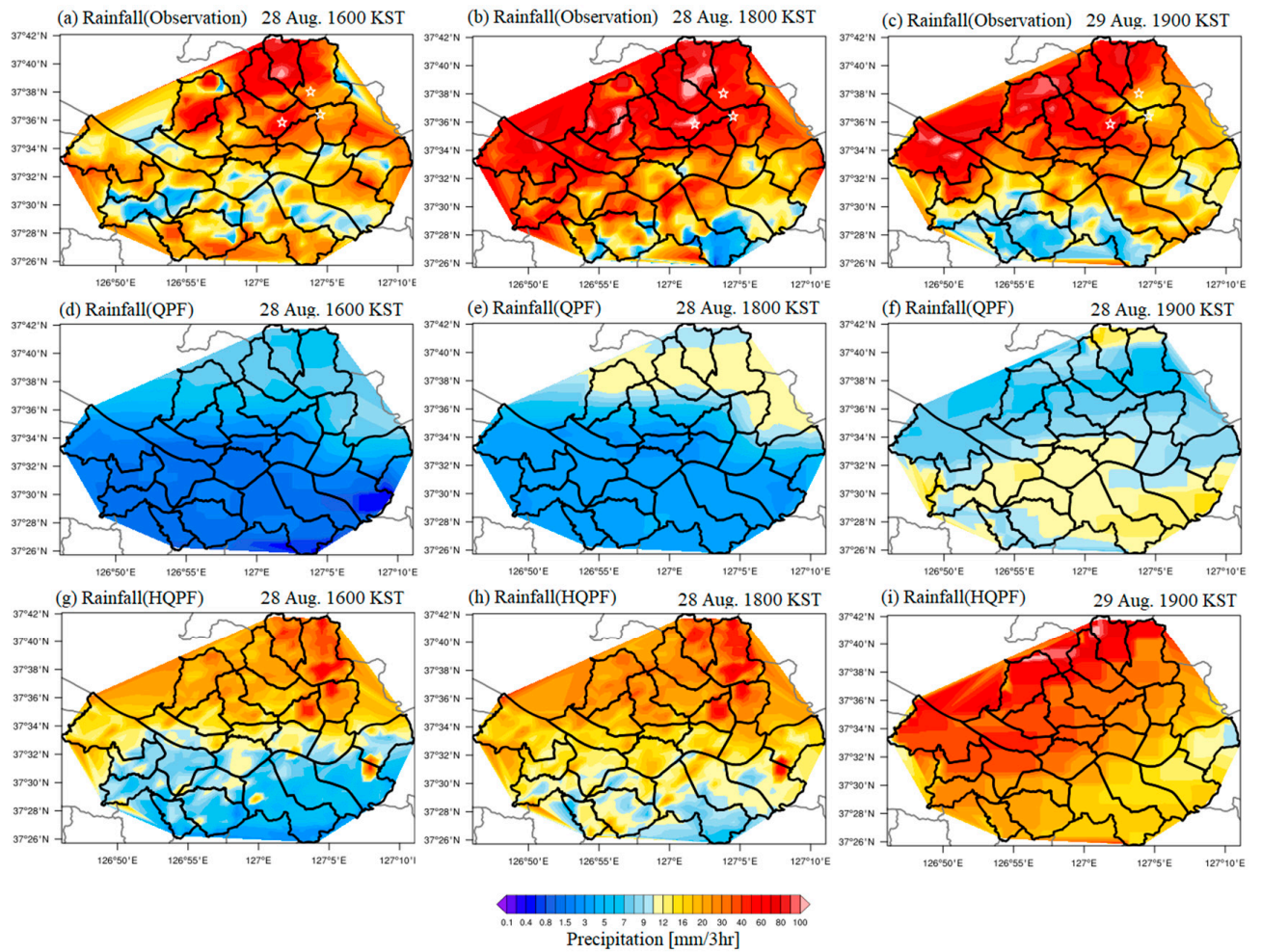

Figure 7. Spatial distribution of a $3 \mathrm{~h}$ accumulated rainfall for observation (upper panels), quantitative precipitation forecast (QPF) (middle panels), and HQPF (lower panels) at 16:00 on August 28 (a,d,g), 18:00 on August $28(\mathbf{b}, \mathbf{e}, \mathbf{h})$, and 19:00 on August $29(\mathbf{c}, \mathbf{f}, \mathbf{i})$. The black line in the map denotes the administrative division of the Seoul area, and the stars in $(\mathbf{a}-\mathbf{c})$ indicate the four sites, Nowon, Jungnang, Dobong, and Gangnam listed in Table 3.
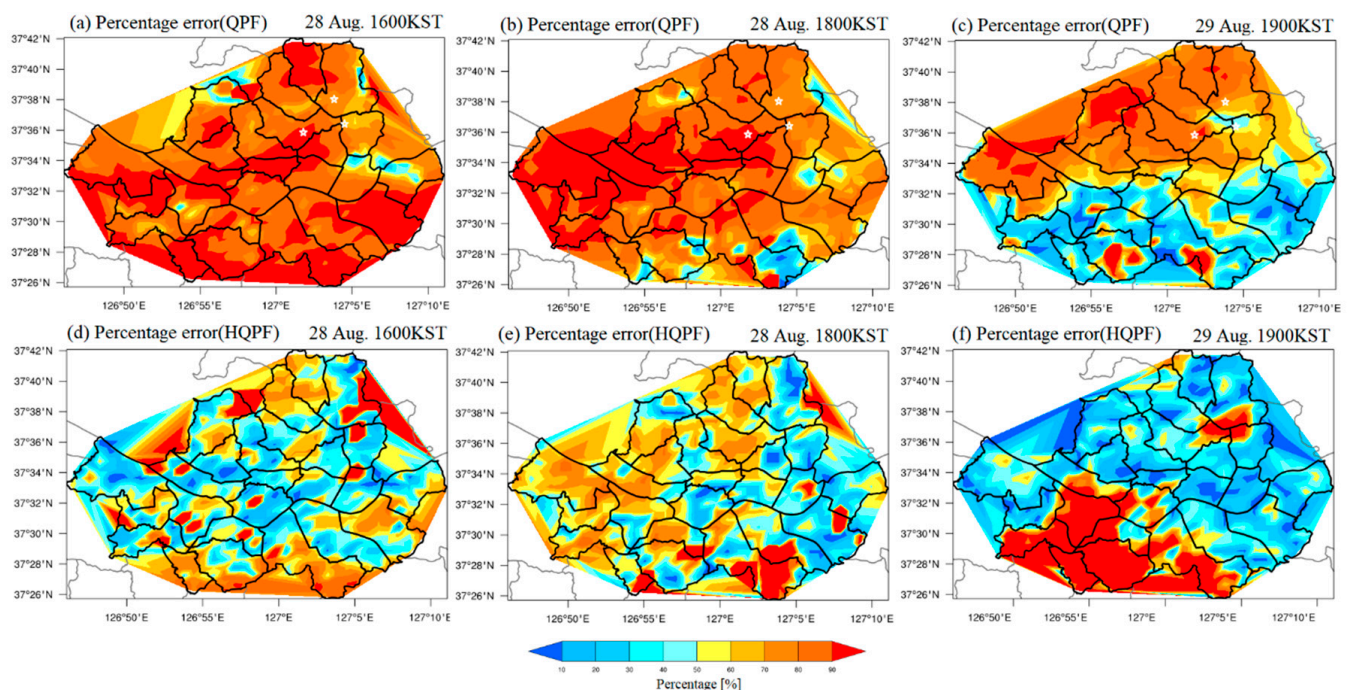

Figure 8. Spatial distribution of percentage error derived from (a-c) QPF-based rainfall and (d-f) HQPF-based rainfall. 


\subsubsection{Time Series Distribution}

In the above analysis on spatial distribution, the localized heavy rainfall occurred mostly over north Seoul; therefore, the study identified the time series for the three sites, Nowon, Jungnang, and Dobong, that represented the north. An additional analysis of Gangnam, which is located in the southern part of Seoul, was conducted for the verification of performance of HQPF. For the time series analysis, we selected the two different time segments that possessed observed peaks. This was because, except for Dobong station, the temporal evolution of rainfall exhibited multiple peaks. Although the skill in simulating the maximum peak is the most important, it is more desirable to capture relatively weak peaks as well. Therefore, data were carried out in two segments to verify the performance of QPF and HQPF. Information on the rainfall shown in Figure 9 is summarized in Table 5. The percentage errors for the peak rainfall of the forecasting results of QPF and HQPF in comparison with the observed are provided in Table 4.
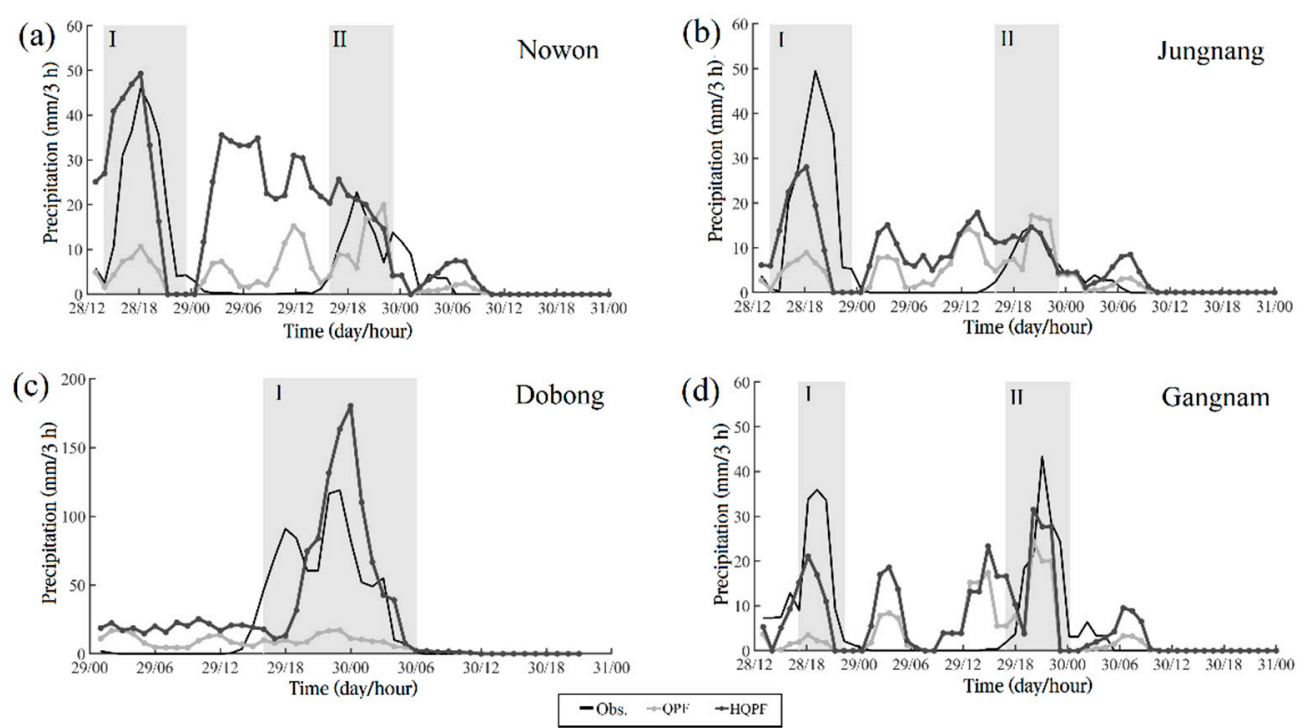

Figure 9. Time series for a $3 \mathrm{~h}$ accumulated rainfall at (a) Nowon, (b) Jungnang, (c) Dobong, and (d) Gangnam observational sites.

Table 5. The intensity of peak precipitation $(\mathrm{mm} / 3 \mathrm{~h})$ and percentage error $(\%)$ by period.

\begin{tabular}{cccccccc}
\hline \multicolumn{7}{c}{ Peak Value (mm/3 h) (Percentage Error (\%)) } \\
\hline $\begin{array}{c}\text { Prediction } \\
\text { Data }\end{array}$ & Nowon-I & Nowon-II & Jungnang-I & Jungnang-II & Dobong-I & Gangnam-I & Gangnam-II \\
\hline QPF & $10.7(76.7)$ & $20(12.3)$ & $8.9(82.0)$ & $17.2(16.2)$ & $17.2(85.6)$ & $3.5(90.3)$ & $24.4(43.6)$ \\
HQPF & $49.3(7.2)$ & $25.7(12.7)$ & $28(43.4)$ & $14.6(1.4)$ & $180.4(51.6)$ & $21.1(41.2)$ & $31.5(27.3)$ \\
\hline
\end{tabular}

In Nowon, in Figure 9a, the maximum rainfall was observed at 18:00 on 28 August, with $46 \mathrm{~mm} / 3 \mathrm{~h}$. For the period, rainfall was $10.7 \mathrm{~mm} / 3 \mathrm{~h}$ through QPF, whereas $49.3 \mathrm{~mm} / 3 \mathrm{~h}$ through HQPF. When calculating the errors in percentage in comparison with the observed, they were $76.7 \%$ for QPF and 7.2\% for HQPF. In section II for Nowon, the rainfall was $20 \mathrm{~mm}$ for QPF and $25.7 \mathrm{~mm}$ for HQPF with the percentage errors of $12.3 \%$ and $12.7 \%$, respectively.

In section I for Jungnang, $8.9 \mathrm{~mm} / 3 \mathrm{~h}$ of rainfall was predicted by QPF, but HQPF predicted a heavier rainfall of $28 \mathrm{~mm} / 3 \mathrm{~h}$. There was underestimation for both the QPF and HQPF, compared to the observed; however, in terms of the percentage error, the HQPF predicted the rainfall twice as accurately as the QPF. In period II for Jungnang, QPF and HQPF produced $17.2 \mathrm{~mm} / 3 \mathrm{~h}$ and $14.6 \mathrm{~mm} / 3 \mathrm{~h}$, with the percentage errors of $16.2 \%$ and $1.4 \%$, respectively. The difference in the absolute value between the observed and HQPF, which had a lower percent error, was only $0.2 \mathrm{~mm} / 3 \mathrm{~h}$. 
Out of the three sites of the study, Dobong recorded the peak precipitation $(119.0 \mathrm{~mm} / 3 \mathrm{~h})$. During the study period, QPF predicted $17.2 \mathrm{~mm} / 3 \mathrm{~h}$, which does not satisfy the heavy rainfall definition, and the percentage error was $85.6 \%$. HQPF predicted $180.4 \mathrm{~mm} / 3 \mathrm{~h}$, which satisfies the definition, but was still overestimated, with $51.6 \%$ of percentage error.

In Gangnam in Figure 9d, the maximum rainfall was $3.5 \mathrm{~mm} / 3 \mathrm{~h}$ with QPF, but $21.1 \mathrm{~mm} / 3 \mathrm{~h}$ through HQPF. When calculating the errors in percentage in comparison with the observed, they were 90.3\% for QPF and $41.2 \%$ for HQPF. In section II for Gangnam, the rainfall was $24.4 \mathrm{~mm}$ for QPF and $31.5 \mathrm{~mm}$ for HQPF, with the percentage errors of $43.6 \%$ and $27.3 \%$, respectively.

The percentage error for Nowon-II was $12.3 \%$ and $12.7 \%$ by QPF and HQPF, respectively, which means that the difference between the two is $1 \%$ or less in Table 5 and Figure 10. However, the difference was identified by a factor from 1.7 times to 11.6 times across the sections. For the maximum rainfall period for each of the sites, Nowon-I showed the percentage error of $75.7 \%$ and $7.2 \%$ for QPF and HQPF, respectively, with a difference by a factor of 1.6 times. Furthermore, it was 1.9 times and 11.6 times for Jungnang-I and Jungnang-II, respectively. For Dobong-I, the percentage error of QPF and HQPF was $85.6 \%$ and $51.6 \%$, respectively, with a difference by a factor of 1.7 times. As a result, for the peak rainfall, HQPF improved the error by up to 11.6 times from the level of QPF. It was 2.2 times and 1.6 times for Gangnam-I and Gangnam-II, respectively.

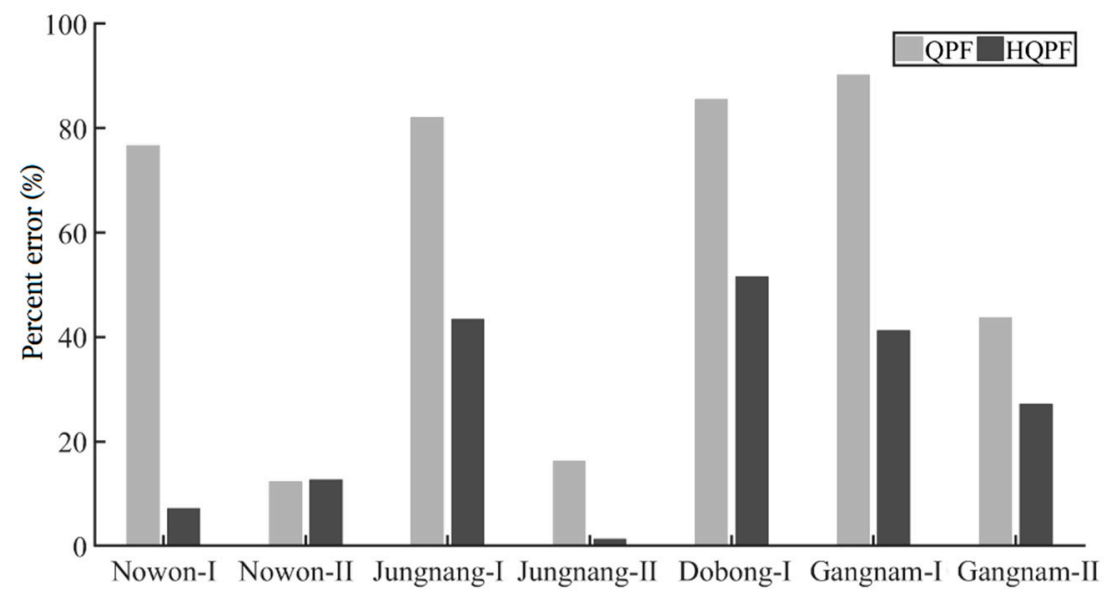

Figure 10. Comparison of the percentage errors in Table 5.

\subsubsection{Analysis of Statistical Error}

For the rainfall correction results to be used for hydrological purposes, the evaluation should be conducted with a focus on the period of localized heavy rainfall (rainfall section I). Therefore, in Section 3.1.3, statistical verification is made for the MAE and NPE, and the result is summarized in Tables 6 and 7.

Table 6. MAE $(\mathrm{mm} / 3 \mathrm{~h})$ calculated at four sites from QPF-based rainfall and HQPF-based rainfall with respect to a heavy rainfall event in Seoul (section I).

\begin{tabular}{ccccc}
\hline Prediction Data & Nowon & Jungnang & Dobong & Gangnam \\
\hline QPF & 18.6 & 19.4 & 48.7 & 19.1 \\
HQPF & 13.6 & 14.2 & 33.3 & 12.0 \\
Difference & 5.0 & 5.2 & 15.4 & 7.1 \\
\hline
\end{tabular}


Table 7. NPE $(\mathrm{mm} / 3 \mathrm{~h})$ calculated at four sites from QPF-based rainfall and HQPF-based rainfall with respect to a heavy rainfall event in Seoul (section I).

\begin{tabular}{ccccc}
\hline Prediction Data & Nowon & Jungnang & Dobong & Gangnam \\
\hline QPF & -0.77 & -0.82 & -0.85 & -0.90 \\
HQPF & 0.07 & -0.43 & 0.52 & -0.41 \\
\hline
\end{tabular}

The MAE result was $18.6 \mathrm{~mm} / 3 \mathrm{~h}, 19.4 \mathrm{~mm} / 3 \mathrm{~h}, 48.7 \mathrm{~mm} / 3 \mathrm{~h}$, and $19.1 \mathrm{~mm} / 3 \mathrm{~h}$ through QPF and $13.6 \mathrm{~mm} / 3 \mathrm{~h}, 14.2 \mathrm{~mm} / 3 \mathrm{~h}, 33.3 \mathrm{~mm} / 3 \mathrm{~h}$, and $12.0 \mathrm{~mm} / 3 \mathrm{~h}$ through HQPF, for Nowon, Jungnang, Dobong, and Gangnam, respectively. For all four sites, HQPF showed a lower error than QPF, and the difference between QPF and HQPF was $5.0 \mathrm{~mm} / 3 \mathrm{~h}$ for Nowon, $5.2 \mathrm{~mm} / 3 \mathrm{~h}$ for Jungnang, $15.4 \mathrm{~mm} / 3 \mathrm{~h}$ for Dobong, and $7.1 \mathrm{~mm} / 3 \mathrm{~h}$ for Gangnam.

As shown in Table 7, all NPEs of QPF had a negative value, with $-0.77,-0.82,-0.85$, and -0.90 , respectively, for Nowon, Jungnang, Dobong, and Gangnam, indicating the underestimation made for rainfall in comparison with the observed. The NPEs of HQPF were $0.07,-0.43,0.52$, and -0.41 , respectively, which means an underestimation for Jungnang and Gangnam and overestimation for Nowon and Dobong. Furthermore, regarding the NPE range of QPF and HQPF, QPF showed errors ranging from 0.77 to 0.90 , while HQPF was from 0.07 to 0.52 . As a result, considering that the values close to zero (0) have a higher similarity with the observed, the study found an enhanced forecast performance for localized heavy rainfall from the HQPF's results, which were produced through machine learning.

\subsection{Case 2: Typhoon Kong-Rey (1825)}

In this chapter, we analyzed the amount of precipitation that fell on the Korean Peninsula during Typhoon Kong-rey. As seen in radar images (see Figure 6), Typhoon Kong-rey brought a very intense and localized rain band, which can provide a good opportunity to compare the accuracy of the rainfall forecast from the QPF raw output and the HQPF corrected output. Using the observations, the distribution of precipitation on the Korean Peninsula was compared (Section 3.2.1), and the performance of QPF and HQPF was verified by selecting four observation stations (Section 3.2.2).

\subsubsection{Spatial Distribution}

In the spatial distribution of the observed precipitation, as shown in Figure 11a-c, one can see that the rain bands exist in the northwest (Gyeonggi, Chungcheong, and Jeolla provinces) and the southeast of Korea. In the spatial distribution of QPF in Figure 11e,f, precipitation in Jeju Island was not simulated at $0700 \mathrm{KST}$ and $0800 \mathrm{KST}$, and the precipitation area of more than $10 \mathrm{~mm} / 3 \mathrm{~h}$ in Gyeonggi Province was smaller than observed. In Figure 11g-i, a precipitation distribution similar to observation was found in Chungcheng and northern Jeolla Province at 0600 KST and 0700 KST. In particular, at 0800 KST, HQPF simulated precipitation in Gyeonggi Province, including Seoul and southeastern Korea, while QPF failed to simulate precipitation.

\subsubsection{Analysis of Statistical Error}

For the four stations shown in Figure 1b, this study investigated the location, time, and amount of maximum precipitation in the observations (Figure 12). At all stations, it was obvious that the maximum precipitation occurred on 6 October, and the observed times of the maximum rainfall were 06:00 in Dangjin, Seosan, and Taean and 09:00 at Bamsagol station. The maximum precipitation accumulated over the three-hour period was $36 \mathrm{~mm}$ (Dangjin), $48 \mathrm{~mm}$ (Baemsagol), $33.8 \mathrm{~mm}$ (Seosan), and $33 \mathrm{~mm}$ (Taean) (Table 8). 

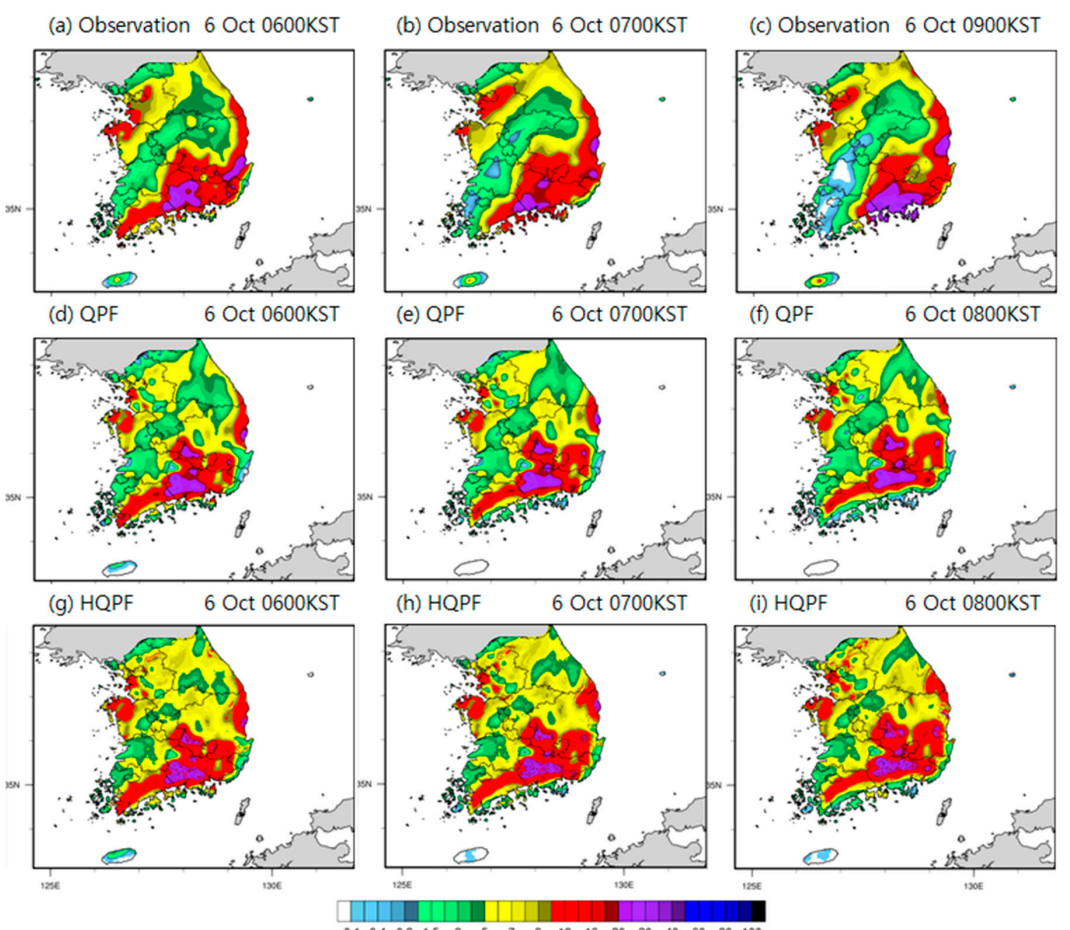

Precipitation $[\mathrm{mm} / \mathrm{shr}]$

Figure 11. Spatial distribution of a $3 \mathrm{~h}$ accumulated rainfall for observation (upper), QPF (middle), and HQPF (lower) at 6:00 (a,d,g), 7:00 (b,e,h), and 8:00 (c,f,i) on 6 October.
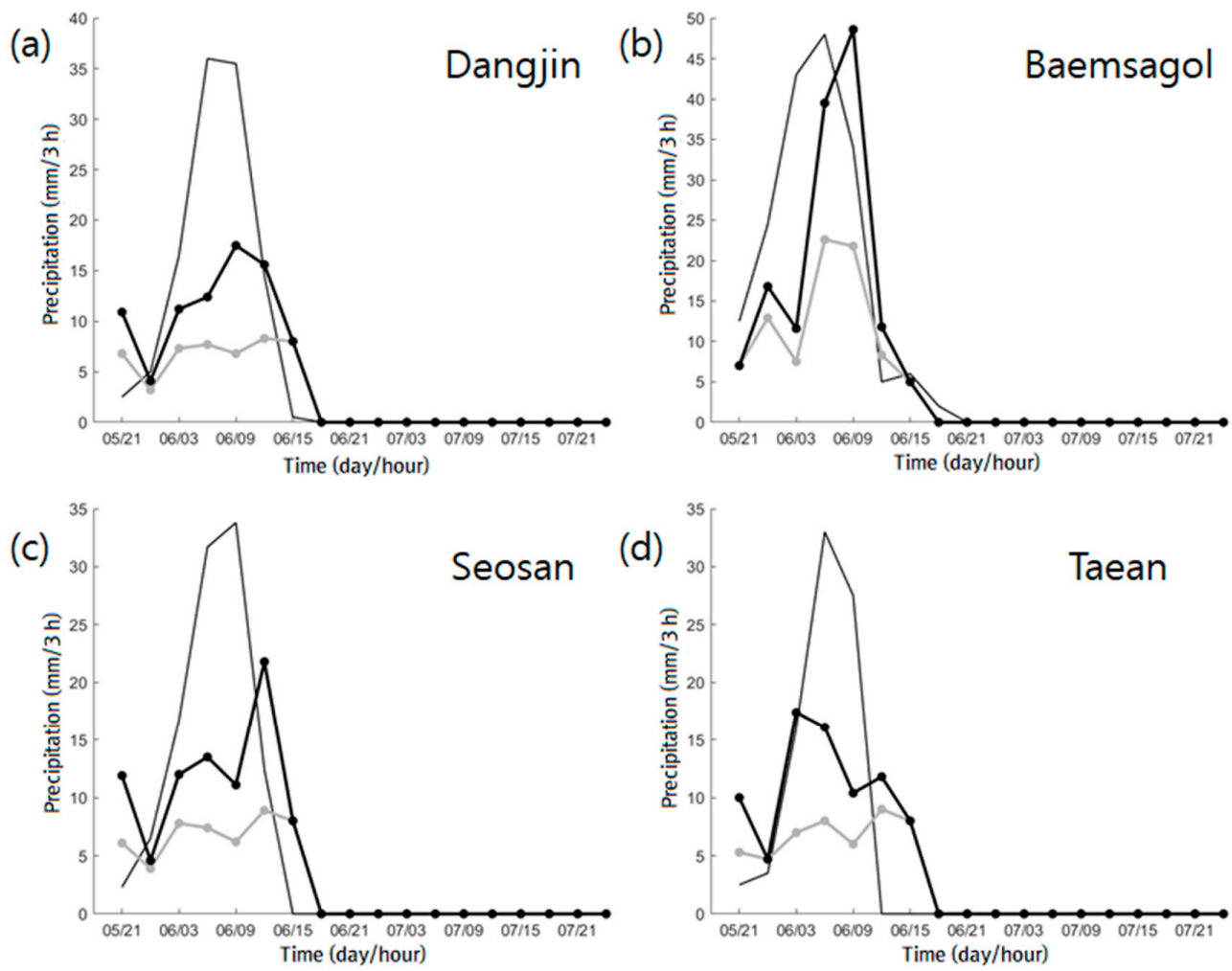

$$
\text { Obs. } \multimap \text { QPF } \multimap \text { HQPF }
$$

Figure 12. Time series (from 21:00 on 5 October to 21:00 on 7 October) for a $3 \mathrm{~h}$ accumulated precipitation at (a) Dangjin, (b) Baemsagol, (c) Seosan, and (d) Taean observational sites. 
Table 8. Rainfall information of the four sites from the observational data.

\begin{tabular}{ccccc}
\hline Information & Dangjin & Baemsagol & Seosan & Taean \\
\hline $\begin{array}{c}\text { Maximum precipitation time } \\
(\text { KST) }\end{array}$ & $06: 00,6$ th & $06: 00,6$ th & $09: 00,6$ th & $06: 00,6$ th \\
Peak precipitation $(\mathrm{mm} / 3 \mathrm{~h})$ & 36 & 48 & 33.8 & 33 \\
\hline
\end{tabular}

The maximum precipitation was investigated for QPF and HQPF during the typhoon (21:00 5 October-21:00 7 October). As shown in Table 9, the maximum precipitation values of QPF were 8.3, 22.6, 8.9, and $9 \mathrm{~mm}$, respectively, for Dangjin, Bamsagol, Seosan and Taean. The values of HQPF were $17.5,48.6,21.8$, and $17.4 \mathrm{~mm}$, respectively.

Table 9. Peak precipitation (mm/3 h).

\begin{tabular}{ccccc}
\hline \multicolumn{4}{c}{ Peak Precipitation $(\mathbf{m m} / \mathbf{3} \mathbf{~ h})$} \\
\hline Prediction Data & Dangjin & Baemsagol & Seosan & Taean \\
\hline QPF & 8.3 & 22.6 & 8.9 & 9 \\
HQPF & 17.5 & 48.6 & 21.8 & 17.4 \\
\hline
\end{tabular}

As shown in Table 10, all NPEs of QPF had a negative value, with $-0.77,-0.53,-0.74$, and -0.73 , respectively, for Dangjin, Bamsagol, Seosan, and Taean, indicating the underestimation made for rainfall in comparison with the observed. The NPEs of HQPF were $-0.51,0.01,-0.36$, and -0.47 , respectively, and these mean an underestimation for Dangjin, Seosan, Taean and overestimation for Bamsagol. Furthermore, regarding the NPE range of QPF and HQPF, QPF showed errors ranging from 0.53 to 0.77 , while HQPF showed errors from 0.01 to 0.51 . As a result, this section found an enhanced forecast performance during Typhoon Kong-rey from HQPF's results, which were produced through machine learning, as in case 1.

Table 10. NPE (mm/3 h) by rainfall.

\begin{tabular}{ccccc}
\hline Prediction Data & Dangjin & Baemsagol & Seosan & Taean \\
\hline QPF & -0.77 & -0.53 & -0.74 & -0.73 \\
HQPF & -0.51 & 0.01 & -0.36 & -0.47 \\
\hline
\end{tabular}

\section{Discussion}

This study developed a machine learning-based rainfall correction technique for Seoul and, its results were compared with the observed results. The study aimed to predict an absolute value of the observed rainfall for a heavy rainfall period. HQPF had a better performance than QPF in predicting rainfall for a heavy rainfall period. When compared with QPF, HQPF used the same data but it reflected the learning, which was the results from past rainfall cases, through the machine learning, for the rainfall correction. Therefore, HQPF is able to predict in a better and quicker way by using big data-based information, which has a nonlinear relationship, at the same time considering the complex process of rainfall. In particular, the effective provision of heavy rainfall information using HQPF will efficiently support the measures for public facilities and disaster prevention in downtowns.

Regarding the performance of predicting localized rainfall, HQPF provided a better result than QPF, but there was still a limitation, which was the difference in the rainfall area between the observed and the predicted. It is normal that such limitation is experienced in forecasting for localized heavy rainfall that occurs by a complex interaction of mid-scale convective system and synoptic-scale forcing. However, efforts are required to improve the spatial prediction and overcome the limitations.

Machine learning-based HQPF is to reduce the uncertainty of rainfall forecasting information, as shown in the case of Typhoon Kong-rey, which showed the results of HQPF to be better than 
QPF. However, even in this case, precipitation peak values were not corrected rather than observed rainfall. The first reason for this is that the input data of big data-based machine learning requires sufficient weather input data, but the weather input data used in this study were limited. The second reason is that the basic research on the parameter optimization of machine learning is insufficient. Therefore, in order to obtain an improved machine learning-based HQPF, it is suggested that study of machine learning parameter optimization should be preceded with sufficient weather input data for machine learning.

\section{Conclusions}

This study applied the machine learning technique to diverse rainfall data provided by the KMA, for the purpose of generating hydrological rainfall information. To develop the HQPF, the study used the ensemble numerical model data, radar data, station observation data, and Dong-Nae Forecast rainfall data, which were provided by the KMA. The data went through a preprocessing step for the conversion to obtain the same level of temporal and spatial resolutions. By analyzing the predictors, the study obtained the final predictors for machine learning. The machine learning that the study used to consider the processing speed and expandability was XGBoost. Lastly, before the post-processing to produce the final correction rainfall, the average was obtained for correction rainfall by ensemble members that calculated through machine learning.

To evaluate the accuracy of HQPF's prediction applied with machine learning, the study targeted the representative heavy rainfall cases of the Seoul area and typhoon Kong-rey (1825) in 2018. As a result of analyzing the spatial field, unlike QPF, HQPF was able to simulate the localized heavy rainfall area, indicating that the machine learning enhanced the performance of predicting localized heavy rainfall. In addition, as a result of analyzing the MAEs for four sites, the MAEs of QPF were $18.6 \mathrm{~mm} / 3 \mathrm{~h}$ (Nowon), $19.4 \mathrm{~mm} / 3 \mathrm{~h}$ (Jungnang), $48.7 \mathrm{~mm} / 3 \mathrm{~h}$ (Dobong), and $19.1 \mathrm{~mm} / 3 \mathrm{~h}$ (Gangnam), while the MAEs of HQPF were $13.6 \mathrm{~mm} / 3 \mathrm{~h}$ (Nowon), $14.2 \mathrm{~mm} / 3 \mathrm{~h}$ (Jungnang), $33.3 \mathrm{~mm} / 3 \mathrm{~h}$ (Dobong), and $12.0 \mathrm{~mm} / 3 \mathrm{~h}$ (Gangnam), which indicates that the error became lower for all the sites by HQPF. Regarding the NPEs, QPF had -0.77 (Nowon), and -0.82 (Jungnang), -0.85 (Dobong), and -0.90 (Gangnam), while HQPF had 0.07 (Nowon), -0.43 (Jungnang), 0.52 (Dobong), and -0.41 (Gangnam). Regarding the NPEs during typhoon Kong-rey, QPF had -0.77 (Dangjin), -0.53 (Bamsagol), -0.74 (Seosan), and -0.73 (Taean), while HQPF had -0.51 (Dangjin), 0.01 (Bamsagol), -0.36 (Seosan), and -0.47 (Taean). This provides clear evidence that the rainfall correction algorithm improved rainfall information.

Although a significant improvement was made for rainfall information by the rainfall correction algorithm that the study developed, limitations still remain in terms of predicting the peak precipitation and defining areas for rainfall forecasting. Therefore, conducting additional studies is necessary for rainfall types, preceding predictors, and the application of more localized rainfall cases to develop algorithms, producing correction rainfall in a more accurate and efficient way.

Based on the results, additional analyses can be made in the future for diverse heavy rainfall cases to use machine learning for the advancement of the rainfall correction technique. HQPF is expected to contribute to flood predictions and impact forecasts $[11,12]$ and can be utilized as useful data in a wide range of hydrological research fields.

Author Contributions: Conceptualization, C.-M.K. and Y.-M.L.; methodology, C.-M.K.; validation, Y.Y.J.; formal analysis, C.-M.K.; data curation, C.-M.K.; writing—original draft preparation, Y.Y.J.; writing—review and editing, Y.-M.L. and B.-S.K.; supervision, Y.-M.L.; project administration, B.-S.K. All authors have read and agreed to the published version of the manuscript.

Funding: This research was funded by Korean Meteorological Administration Research and Development Program under Grant KMI [2018-03010].

Conflicts of Interest: The authors declare no conflict of interest. 


\section{References}

1. Zamami Joharestani, M.; Cao, C.; Ni, X.; Bashir, B.; Talebiesfandarani, S. PM 2.5 Prediction based on random forest, XGBoost, and deep learning using multisource remote sensing data. Atmosphere 2019, 10, 373. [CrossRef]

2. Valipour, M.; Sefidkouhi, G.; Ali, M.; Raeini-Sarjaz, M.; Guzman, S.M. A hybrid data-driven machine learning technique for evapotranspiration modeling various climates. Atmosphere 2019, 10, 311. [CrossRef]

3. Ghada, W.; Eastrella, N.; Meanzel, A. Machine learning approach to classify rain type based on this disdrometers and cloud observations. Atmosphere 2019, 10, 251. [CrossRef]

4. Hong, W.C. Rainfall forecasting by technological machine learning models. AMC 2008, 200, 41-57. [CrossRef]

5. Kang, B.S.; Lee, B.K. Application of artificial neural network to improve quantitative rainfall. JKWRA 2011, 44, 97-107.

6. Parmar, A.; Mistree, K.; Sompura, M. Machine learning techniques for rainfall prediction: A Review. In Proceedings of the 2017 International Conference on Innovations in Information Embedded and Communication Systems, Coimbatore, India, 17-18 March 2017.

7. Sumi, S.M.; Zaman, M.F.; Hirose, H. A rainfall forecasting method using machine learning models and its application to the Fukuoka city case. Int. J. Appl. Math. Comput. Sci. 2012, 22, 841-854. [CrossRef]

8. Chen, T.; He, T. xgboost: eXtreme Gradient Boosting. Available online: https://cran.r-project.org/web/ packages/xgboost/vignettes/xgboost.pdf (accessed on 16 January 2020).

9. Friedman., J.H.; Hastie, T.; Tibshirani, R. Additive logistic regression: A statistical view of boosting. Ann. Stat. 2000, 28, 337-374. [CrossRef]

10. Ke, G.; Meng, Q.; Finely, T.; Wang, T.; Chen, W.; Ma, W.; Ye, Q.; Liu, T.Y. LightGBM: A highly efficient gradient boosting decision tree. In Proceedings of the 31st Conference on Neural Information Processing Systems, Long Beach, CA, USA, 4-9 December 2017; pp. 3149-3157.

11. Kim, B.S.; Kim, B.K.; Kim, H.S. Flood simulation using the gauge-adjusted radar rainfall and physics-based distributed hydrologic model. Hydrol. Process. 2008, 22, 4400-4414.

12. Met Office. Flood Guidance Statement User Guide; Environment Agency: Bristol, UK, 2017.

(C) 2020 by the authors. Licensee MDPI, Basel, Switzerland. This article is an open access article distributed under the terms and conditions of the Creative Commons Attribution (CC BY) license (http://creativecommons.org/licenses/by/4.0/). 